SVU- International Journal of Veterinary Sciences, 3 (2): 1-13, 2020.

Print ISSN: 2535-1826

\title{
Clinicopathological and Hematological Changes in Consequence to Experimental Infection of Rabbits with Pasteurella Multocida Type A
}

Abeer HM El-Hendy ${ }^{1}$, Fatma M Mohamed ${ }^{* 2}$, Ahmed K Hassan ${ }^{3}$

${ }^{1}$ Pathology Department, Assiut Regional Laboratory, Animal Health Research Institute, Agricultural Research Center (ARC), Egypt, ${ }^{2}$ Poultry Diseases, Assiut Regional Laboratory, Animal Health Research Institute, Agricultural Research Center (ARC), Egypt, ${ }^{3}$ Department of Poultry diseases, Faculty of Veterinary Medicine, Assiut University, Egypt

\section{Abstract}

The current research aimed to study clinical, hematological and pathological changes occurred due to experimentally challenged rabbits with Pasteurella multocida type A. Twelve healthy Pasteurella multocida free rabbits were divided into control and challenged groups. Rabbits of the challenged group were intra-nasally inoculated with $0.5 \mathrm{ml}$ of $1 \times 10^{5} \mathrm{CFU}$ of Pasteurella multocida type A, while rabbits of the control group were inoculated with $0.5 \mathrm{ml}$ of brain heart infusion broth (BHI). Clinical signs, hematological parameters and histopathological lesions were recoded for 14 days. Rabbits of challenged group showed nasal rubbing with minimal mucus discharge, conjunctivitis and reduction in spontaneous activity, but no mortality occurred. Hematologically, there was highly significant low RBCs count with concomitant significantly reduction of PCV in challenged rabbits, but hemoglobin concentration was insignificantly low in challenged animals as compared to control. Although, there was insignificant increase of WBCs count in challenged group, neutrophils and monocytes recorded significant and highly significant high value in challenged rabbits than control, respectively. Challenged rabbits, however demonstrated highly significant lymphopenia, but other blood parameters did not show any significant differences between challenged and control rabbits. Histopathologically, challenged animals showed meningitis, congestion and degenerative changes in respiratory epithelium, bronchopneumonia, vacuolar degeneration of hepatocytes and vascular changes in heart and spleen. Conclusively, the current study verified that challenging rabbits with Pasteurella multocida serotype A was not lethal and although it was essentially pneumotropic in nature, it caused lesions in other visceral organs, which in absence of bacteremia, could be caused by bacterial endotoxin liberated during disease pathogenesis.

Keywords: Experimental infection, Hematological parameters, Histopathological lesions, Pasteurella multocida.

DOI: $10.21608 / \mathrm{svu} .2020 .28129 .1048$

Received: April 17, $2020 \quad$ Accepted: May 03, 2020

*Corresponding Author: Fatma M. Mohamed

Published: May 07, 2020

E-mail: elzuhry@yahoo.com

Citation: El-Hendy et al., Clinicopathological and Hematological Changes in Consequence to Experimental Infection of Rabbits with Pasteurella Multocida Type A. SVU-IJVS 2020, 3 (2): 1-13.

Copyright: (C) El-Hendy et al. This is an open access article distributed under the terms of the creative common attribution license, which permits unrestricted use, distribution and reproduction in any medium provided the original author and source are created.

Competing interest: The authors have declared that no competing interest exists. 


\section{Introduction}

Rabbit pasteurellosis considered one of most significant causes of economic losses in large production units throughout the world (Stelian et al., 2011). It is bacterial disease caused by Pasteurella multocida, which is considered a normal opportunistic microorganism of upper respiratory tract in a range of animal species (Suelam and Samie, 2011) including cattle, swine, canine, fowl and rabbits (Harper et al., 2006; Hotchkiss et al., 2011, Suelam and Samie, 2011). Pasteurella multocida is a Gram-negative coccobacillus, non-motile, non-spore-forming and facultative anaerobic bacterium that shows bipolar staining with Giemsa stain (Carter, 1987). By using serological techniques $P$. multocida is classified on the base of capsular antigens into five capsular serogroups (A, B, D, E and F), and into 16 somatic serotypes (1-16), based on lipopolysaccharide antigens (Rimler and Rhoades, 1989). Rabbit pasteurellosis mainly caused by the capsular type A and a lesser extent by capsular type D strains (Dabo et al., 1999; Katoch et al., 2015), that may vary in clinical symptoms as (respiratory distress, conjunctivitis, otitis, genital infection, meningitis and abscesses) also $P$. multocida may don't show any clinical signs (Delong and Manning, 1994; Asran et al., 2016). The clinical signs variability as well as the course of the disease may be influenced by different virulence factors of $P$. multocida such as polysaccharide capsule, lipopolysaccharides (endotoxins), fimbria, exotoxins, extracellular enzymes and plasmids (Harper et al., 2006) .The infection often acquired from a carrier dam and the disease developed when the animals are exposed to stress factors like transportation (Asran et al., 2016). It has been estimated that the prevalence of $P$. multocida in clinically healthy animals (rabbits or other animal species) range from 20 to $90 \%$ depending on the detection methods applied (Sanchez et al., 2004), and it commonly affect rabbits at age of 4 to 8 weeks but rabbits older than 8 months to one year exhibited lesser incidence (ElGhawy, 1972). It was reported that intranasal inoculation of rabbit with $P$. multocida resulted into marked inflammation in respiratory tract leading to congestion, hemorrhages, edema, and infiltration of inflammatory cells with fibrin deposition resulting in to fibrinosuppurative bronchopneumonia (Patel et al., 2016). It was estimated that $P$. multocida infection in rabbits cause significant changes only in erythrocytes, hemoglobin, hematocrit and mean concentration of corpuscular hemoglobin (Petrova et al., 2017). This research work aimed to study the clinical, hematological and histopathological changes in rabbits experimentally infected with $P$. multocida type A.

\section{Materials and Methods Animals}

The study was conducted on 12 healthy pasteurellosis free, 11 to 12 weeks age adult New Zealand White (NZW) rabbits of either sex (weighing 1000-1200g and aging 11-12 weeks) obtained from Rabbit Production Unit, Faculty of Agriculture, Assiut University, Assiut, Egypt. In addition, two adult male mice were obtained from the Animal house, Faculty of Veterinary Medicine, Assiut University, Egypt. Rabbits and the two mice were maintained under standard management conditions. For feeding, conventional standard laboratory diet was used with free access to water. Animal care, housing, and environmental conditions (temperature, humidity and light dark cycle) were applied according to the recommendations in the 
Guide for Care and Use of Laboratory Animals (Committee for the Update of the Guide for the Care and Use of Laboratory Animals, 2011) before and during the study period. Animals were identified by the use of permanent marker on the ear.

\section{Pasteurella multocida live culture:}

$P$. multocida live culture (of rabbit origin) was obtained on $5 \%$ blood agar slant from Serology Unit and Bacterial Strains Bank, Animal Health Research Institute, Dokki. The isolate was streaked onto different blood agar plates to obtain an isolated colony for further use in experiment.

\section{Passage in mice for virulence:}

A loopful of the culture was dissolved in $0.5 \mathrm{ml}$ sterile PBS and injected in mice intraperitoneally using an insulin syringe. Following the death of mice after $48 \mathrm{~h}$, postmortem was done under aseptic conditions. Blood was collected from heart and streaked on 5\% blood agar, incubated overnight at $37 \mathrm{oC}$. Separate colonies were obtained and used for inoculation in healthy rabbits.

\section{Pre-inoculation testing:}

The experimental rabbits were checked for $P$. multocida free status. Sterile swab was deeply inserted in either nares of rabbits and cultured on 5\% blood agar media. The grown culture on blood agar was subjected to Giemsa staining. The smears were free from the bipolar $P$. multocida coccobacilli.

\section{Experimental design}

Twelve healthy $P$. multocida-freerabbits were divided into two groups (control and challenged), six animals each. $0.5 \mathrm{~mL}$ of $1 \times 105 \mathrm{CFU}$ of prepared inoculum was inoculated in each nares using an insulin syringe without needle. Just after inoculation, the head of rabbits were kept in an upward position for 2 min to ensure that the inoculum moved deeply in nasal cavity. The rabbits of the control group were inoculated with $0.5 \mathrm{ml}$ uncultured BHI broth in each naris in the same procedure. Animals were observed for 14 days postinoculation for clinical signs and mortalities. Body temperature was recorded daily with digital thermometer through the rectum.

\section{Sample collection, gross necropsy and histopathology:}

Before necropsy, blood was collected from ear vein in sterile vials with anticoagulant for hematology. At the end of the experiment, animals were sacrificed and necropsied. Samples from the trachea, liver, spleen, heart, kidney and brain were collected in $10 \%$ neutral buffered formalin (NBF) for histopathology. Before fixation, impression smears were prepared from the above-mentioned organs, fixed in methanol and stained with Methylene Blue (EMB) stain for examination of bipolar organisms. Fixed tissues were processed routinely for histopathology according to Bancroft and Gambl (2008). Thin paraffin sections (3$5 \mu \mathrm{m})$ of the tissues were stained with Hematoxylin and Eosin (H \& E) (Suvarna et al. 2013), examined microscopically and photographed.

\section{Hematological indices:}

At the end of experiment (14th day) blood samples were collected from ear veins from each animal. About $2 \mathrm{ml}$ of blood were collected into sterile (EDTA) anticoagulant containing vials for determination of the following hematological parameters; red blood cell (RBC) count, hemoglobin 
concentration, packed cell volume (PCV), mean corpuscle volume (MCV), mean corpuscle hemoglobin concentration, white blood cell (WBC) count and differential leukocytic count using (Medonic Auto Hematology Analyzer CA620/Vet/20)

\section{Statistical analysis:}

Data of hematological parameters are expressed as mean $\pm \mathrm{SD}$. The statistical analysis was performed by using SPSS data analysis software (version 17). The analysis was performed by one-way ANOVA followed by Scheffe and Duncan test, $P$ value $<0.05$ is considered as significance.

\section{Results}

\section{Clinical observation}

The rabbits of the control group revealed no clinical signs, no mortality and no postmortem lesions among them. After 24 hours of intranasal inoculation with $\mathrm{P}$. multocida, the rabbits of challenged group demonstrated nasal rubbing with minimal mucus discharge and reduction in spontaneous activity. Symptoms also included sneezing, affected rabbits made a loud snoring sound or snuffling. Three of the challenged rabbits were demonstrated grooming their faces and nasal discharge appeared on their front paws. Two rabbits demonstrated conjunctivitis and crusting around the eyes. None of these challenged animals died during the two weeks of observation.

\section{Hematological parameters}

The hematology of challenged rabbits revealed striking variations in different parameters as compared to control animals. RBCs count demonstrated highly significant reduction; as a consequence hemoglobin is insignificantly low in challenged rabbits as compared to control. The WBCs revealed non-significantly high values in challenged group as compared to control. In addition, PCV demonstrated significantly low values in challenged group as compared to control. There was non-significant difference between challenged and control animals in MCV. The MCHC, however, demonstrated significantly high value in challenged when compared with control group. Concerning the differential leukocytic count, neutrophils and monocytes recorded significant and highly significant high value in challenged rabbits than those of the control, respectively. Lymphocytes, however, demonstrated highly significant low values in challenged as compared to control animals. No significant difference was demonstrated in the eosinophils (Table 1 and Fig. 1).

Table 1: shows the detailed changes in different hematological parameters (Means \pm SE) in rabbits of control and challenged groups. *Significant $(\mathrm{p}<0.05), * *$ Highly significant $(\mathrm{p}<0.01)$

\begin{tabular}{lcc}
\hline Parameters & Control group & Challenged group \\
\hline RBCs $\left(\mathbf{1 0}^{\mathbf{6}} / \mathbf{m m}^{\mathbf{3}}\right)$ & $5.62 \pm 0.12$ & $4.70 \pm 0.23^{* *}$ \\
Hb $(\mathbf{g} / \mathbf{d l})$ & $10.39 \pm 0.34$ & $10.07 \pm 0.71$ \\
PCV $(\%)$ & $37.95 \pm 0.45$ & $34.09 \pm 1.88^{*}$ \\
MCV(FL) & $71.64 \pm 1.23$ & $69.49 \pm 1.48$ \\
MCHC $(\mathbf{g} / \mathbf{d l})$ & $30.73 \pm 0.48$ & $34.10 \pm 0.63^{*}$ \\
WBC $\left(\mathbf{1 0}^{3} / \mathbf{m m}^{\mathbf{3}}\right)$ & $7.21 \pm 0.20$ & $7.56 \pm 0.33$ \\
Neutrophil $\left(\mathbf{1 0}^{\mathbf{3}} / \mathbf{m m}^{\mathbf{3}}\right)$ & $2.60 \pm 0.20$ & $3.56 \pm 0.21^{*}$ \\
Eosinophil $\left(\mathbf{1 0}^{3} / \mathbf{m m}^{\mathbf{3}}\right)$ & $0.12 \pm 0.007$ & $0.14 \pm 0.01$ \\
Monocyte $\left(\mathbf{1 0}^{3} / \mathbf{m m}^{\mathbf{3}}\right)$ & $0.26 \pm 0.01$ & $0.89 \pm 0.04 * *$ \\
Lymphocyte $\left(\mathbf{1 0}^{\mathbf{3}} / \mathbf{m m}^{\mathbf{3}}\right)$ & $4.30 \pm 0.22$ & $2.90 \pm 0.20^{* *}$ \\
\hline
\end{tabular}




\section{Pathological observation:}

The challenged animals demonstrated various histopathological lesions in the examined organs.

\section{Brain}

Challenged animal showed congested mildly thickened meninges as revealed by gross examination. Microscopically, two rabbits showed some evidence of meningitis in form of lymphocytic inflammatory cells infiltration, hyperemia of blood vessel and edema (Fig. 1 A, B). The pathological changes in the brain glial reaction associated with neuronal degeneration (Fig. 1 C, D).

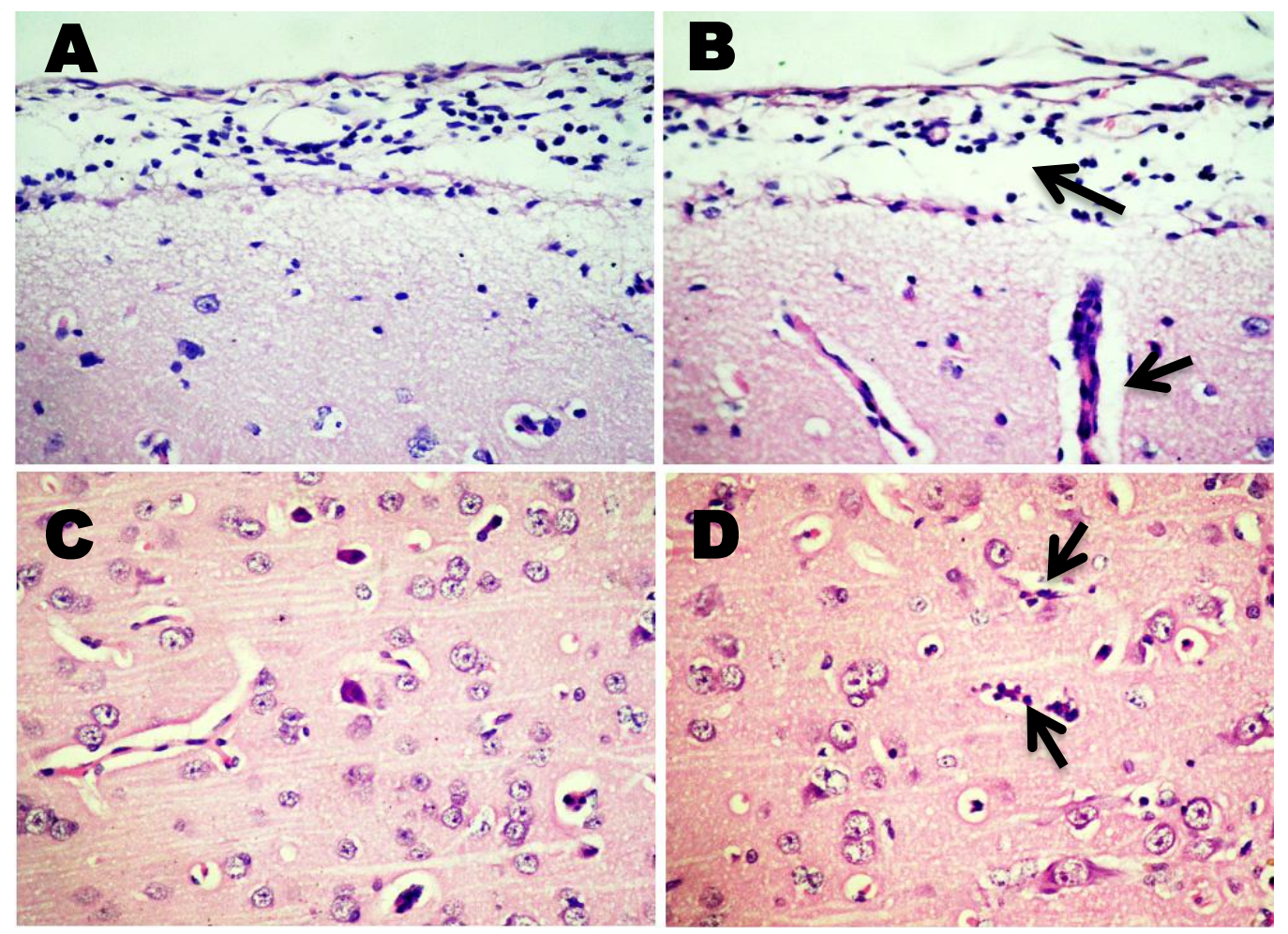

Fig. 1. Brain of rabbit $14^{\text {th }} \mathrm{d}$ post infection with Pasteurella multocida showing (A) Lymphocytic inflammatory cells infiltration in meninges; (B) Infiltration of inflammatory cells, hyperemia of blood vessels and edema (arrows); (C) and (D) Brain showing edema surrounding blood vessels, glial reaction associated with neuronal degeneration (arrows) (H\&E x400).

\section{Trachea}

At time of necropsy tracheal mucosa was moderately reddened and edematous. Microscopically, there was increased number of goblet cells in the tracheal mucosa and submucosal congestion (Fig. 2A). In some parts, the lining epithelium showed desquamation, polymorphonuclear neutrophils, lymphocytes and macrophages infiltrated among the degenerated epithelial cells and in the sub epithelial tissue (Fig. 2B).

\section{Lung}

Grossly, there was mild congestion and variable degrees of pneumonia in the anterior lung lobes with emphysematous areas. Microscopically, the lung showed thickening of inter alveolar septa, mononuclear cellular infiltration, hyperplastic bronchiolar epithelium and fibrinoid necrosis in the wall of pulmonary blood vessel (Fig. 2 C, D). In addition, scattered hemorrhages were demonstrated in 
the alveolar lumen and alveolar emphysema

(Fig. 2 D-F).

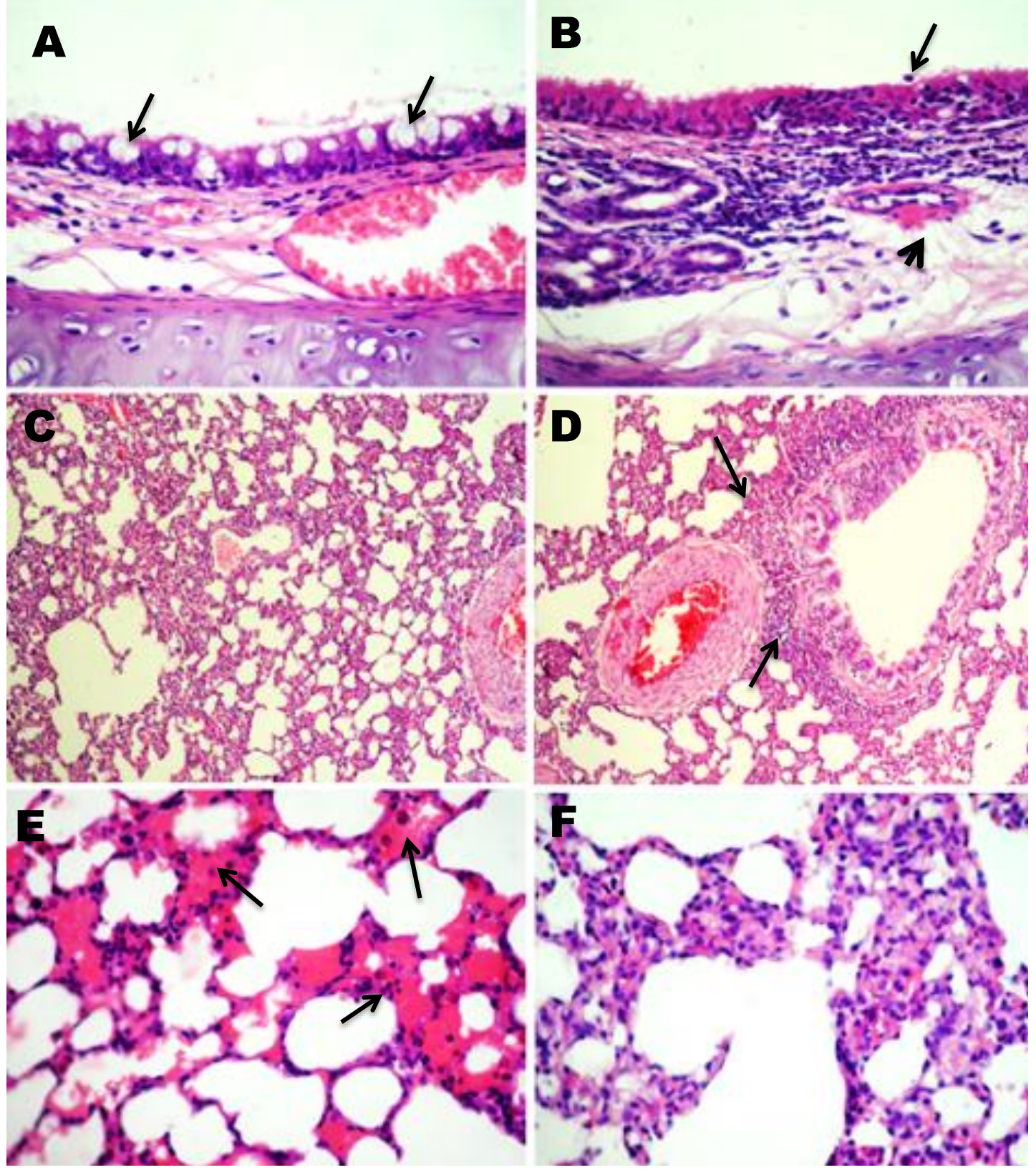

Fig. 2. Trachea and lung of rabbit $14^{\text {th }} \mathrm{d}$ post infection with Pasteurella multocida (A) Trachea shows hypertrophy of goblet cells (arrows), congested and dilated blood vessels (B) Desquamation of epithelial lining (arrow), neutrophils and macrophages infiltration between the degenerated cells and in the sub-epithelial layer and edema in lamina propria (arrow head) (H\&Ex400) (C) Lung shows thickening of inter-alveolar septa (D) Congested pulmonary blood vessels, peri bronchial and peri vascular inflammatory cells infiltration (arrows) (H\&Ex100). (E) Intra- alveolar scattered hemorrhages (arrows) (F) Thickening of inter-alveolar septa and emphysema (H\&Ex400). 
Liver

At necropsy, there were no appreciable lesions in the liver of infected rabbits except congestion. Microscopically, there was diffuse hydropic degeneration and cytoplasmic vacuolation of hepatocytes, marked congestion of blood vessels (Fig.
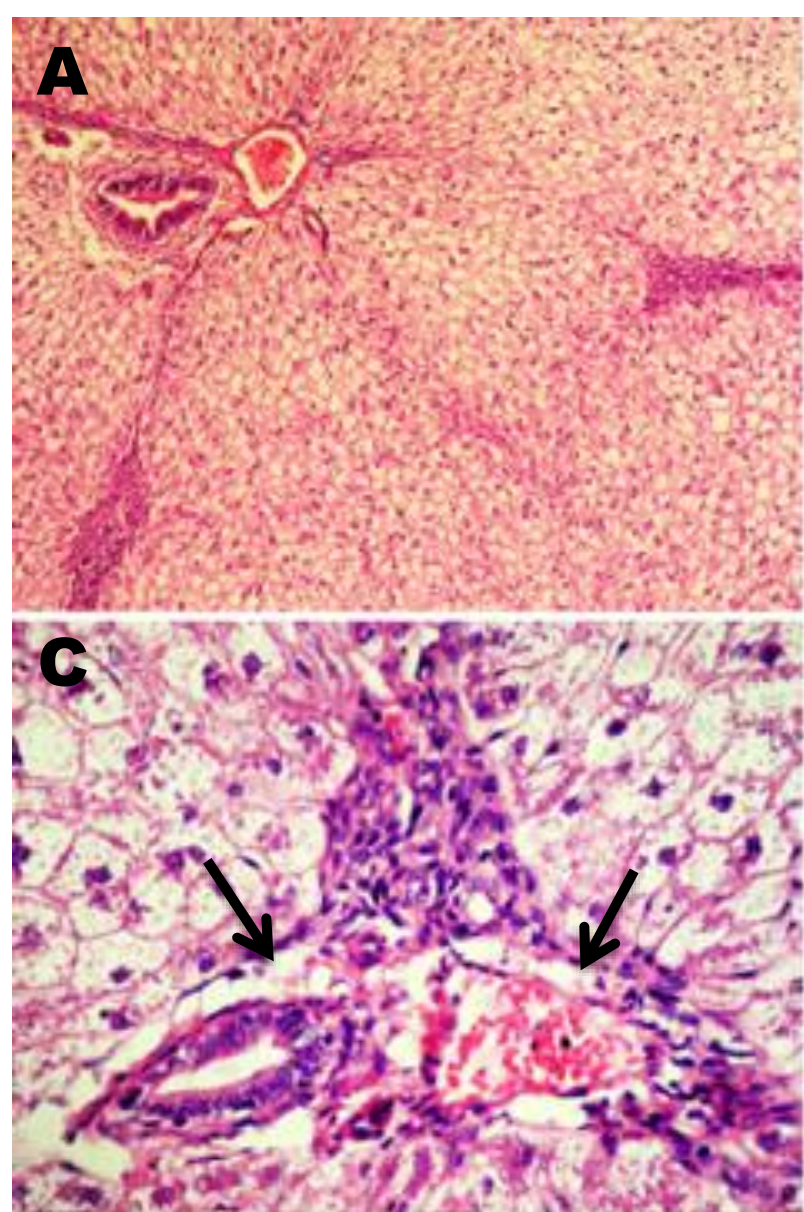

Fig. 3. Liver of rabbit $14^{\text {th }} \mathrm{d}$ post infection with Pasteurella multocida showing (A) Engorged blood vessel and hepatocytes with diffuse hydropic degeneration (H\&E x100) (B) Focal necrosis (arrow) with mononuclear cellular infiltration. (C) Periportal mononuclear inflammatory cells infiltration and congested blood vessel surrounded by edema (arrows). (D) Mononuclear cellular infiltration in portal area associated with fibrosis (arrow) (H\&Ex400).

\section{Heart}

At the time of necropsy mild congestion could be observed in the heart but spleen did not show any gross changes. Microscopically, the lesions in the heart consisted of hemorrhages, engorged blood vessels (Fig. 4 A, B).
3A), scattered necrotic foci infiltrated with mononuclear inflammatory cells (Fig. 3B). In addition, there was periportal mononuclear inflammatory cells infiltration associated with edema and fibrosis (Fig. 3 C, D).
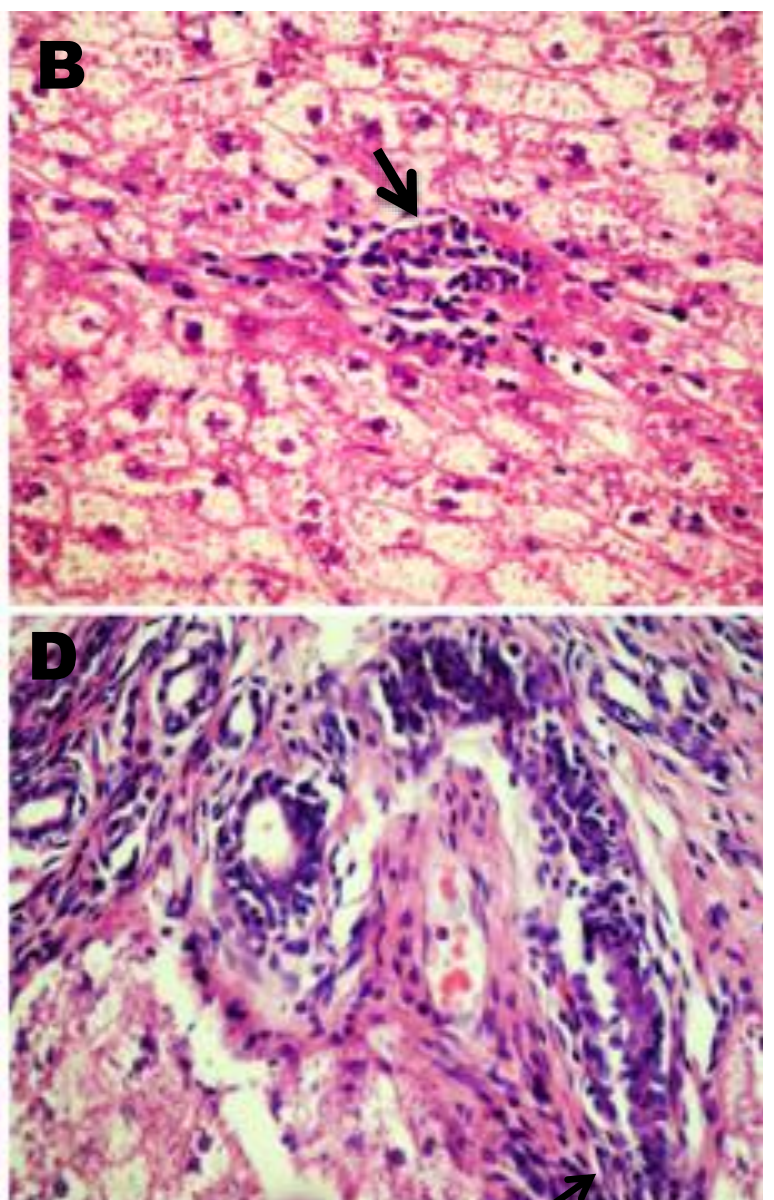

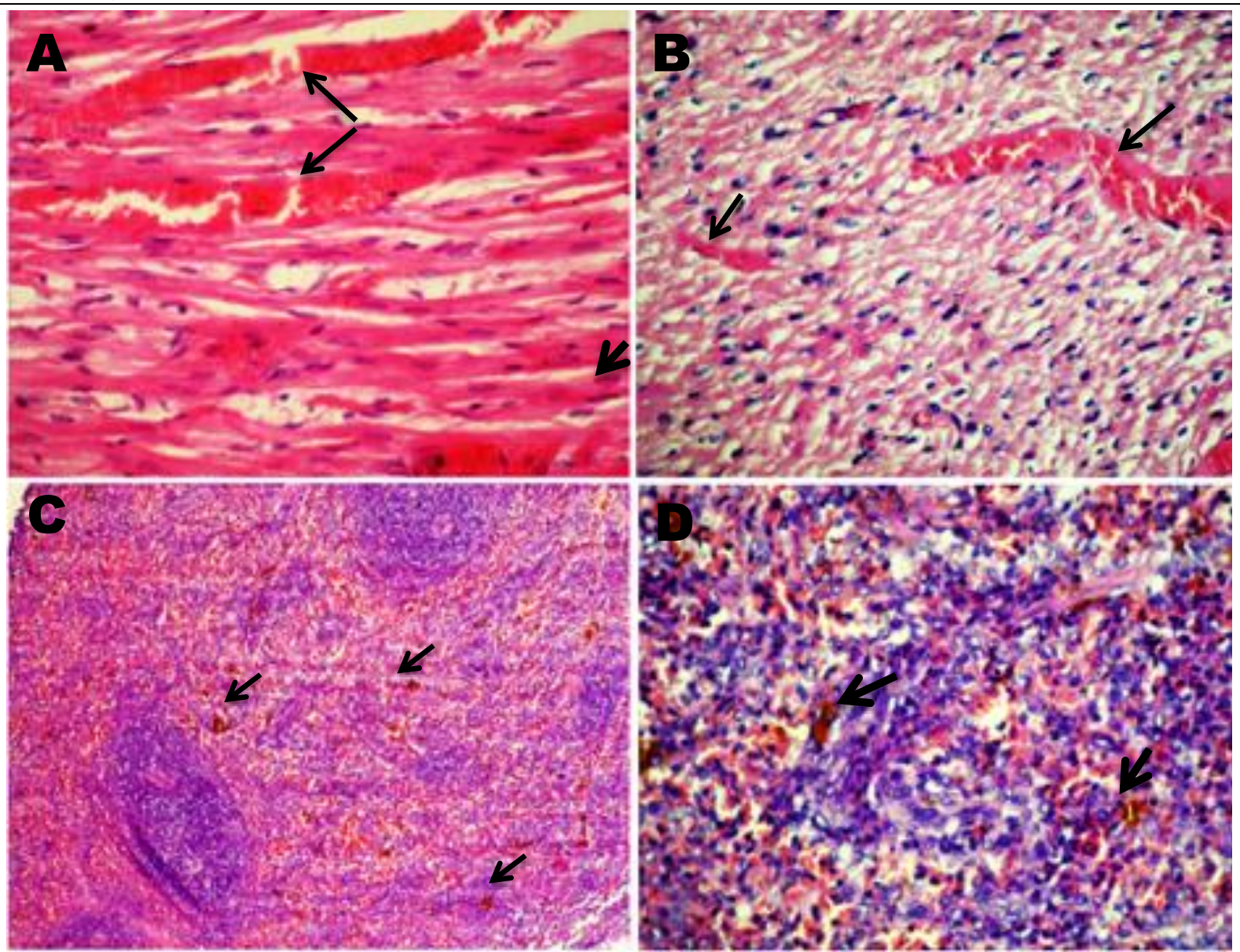

Fig. 4. Heart and spleen of rabbit $14^{\text {th }}$ d post infection with Pasteurella multocida (A) Heart shows interstitial hemorrhage (arrows). (B) Congested blood vessels (arrows) (H\&Ex400). (C) Spleen shows congestion and hemorrhages and slight increase in hemosiderin laden macrophages (arrows) (H\&Ex100). (D) Higher magnification showing hemosiderin-laden macrophages in the red bulb of the spleen (arrows) (H\&Ex400).

\section{Discussion}

The current study aimed to study pasteurellosis in following intranasal challenge with $P$. multocida serotype A. In agreement with Mir et al. (2001) and Praveena et al. (2010), the symptoms which were observed within 14 days after challenge, in the current investigation, started with acute form then subsided to subacute form of the disease. Signs included primarily dullness, rhinitis, sneezing, bronchopneumonia and conjunctivitis, but then decline to subacute form with minimal clinical signs. However, no deaths were observed during the whole experiment. As previously mentioned, $P$. multocida isolated from rabbits demonstrate great differences in the virulence ranging from chronic form of rabbit pasteurellosis (snuffles) to fatal septicemic forms (Glavits and Magyar, 1990). It has been also stated that isolates of $P$. multocida vary in their abilities to induce disease; some are primarily associated with inflammatory conditions in the upper respiratory system, while others may cause septicemia and pneumonia (Chengappa et al., 1982; DiGiacomo et al., 1991). In addition, some other investigations reported 
dyspnoea and abdominal breathing in addition to the above-mentioned symptoms (Al-Haddawi et al. 2001, Jaglic et al. 2006, Rameshkumar et al. 2006).

Regarding hematological parameters, the rabbits of challenged group revealed striking variations as compared to control animals. Although RBCs demonstrated highly significant low count with concomitant significantly reduction of PCV in challenged rabbits, hemoglobin concentration was insignificantly low as compared to control. Similarly, Nassar et al. (2013) and Alam et al. (2018) reported that there was significant reduction in RBC count and PCV\% in P. multocida infected rabbits. The low RBCs count, PCV and hemoglobin accompanying $P$. multocida infections may be due to decrease in the iron release from macrophages to plasma cells with subsequent decrease in RBCs life span (Hoffbrand and Pettit, 1993). In our opinion, the reduction in the RBCs count, PCV and hemoglobin concentration could be attributed to the lysis of RBCs as a result of bacterial toxin accompanying $P$. multocida infections.

In spite of the insignificant increase of WBCs count in challenged group, neutrophils and monocytes recorded significant and highly significant high value in challenged rabbits than those of the control, respectively. However, Al-Jeboori and Rasheed (2014) demonstrated marked leukocytosis associated with increase percentages of the neutrophils, monocytes and lymphocytes in infected group in comparison to control. Contrarily, the current study showed that lymphocytes demonstrated highly significant low values in challenged as compared to control animals. Leukocytosis (increased count of WBCs in blood) has been stated to occur as a result of activation of bone marrow by $P$. multocida antigins (Numata et al., 1998; Carrigan et al., 2004). The increase in the percentages of neutrophils, monocytes, has been attributed to the bacterial toxin of $P$. multocida (Hoffbrand and Pettit, 1993). In the same concern, Ruble et al. (1999) and Alam et al. (2018) believed that neutrophilia in blood of $P$. multocida infected rabbits could be a physiological response from the body to minimize the spread of $P$. multocida infection. While the lymphopenia observed in rabbits of challenged group in our study could be possibly due to infiltration of these cells into the infected tissues or as a result of apoptosis or cytolysis by bacterial toxins (Praveena et al., 2010).

The histopathological changes observed in brain included meningitis, vascular edema and neuronal degeneration. Similarly, Kpodekon (1983) found that rabbits experimentally infected with $P$. multocida through infraorbital nerve, oral rout and intravenous rout revealed meningitis, encephalitis and /or otitis. Kpodekon (1983) assumed that this nerve lesion triggered stagnation of neuronal lymph which provoked retrograde centripetal circulation of lymph up to the brain resulting in meningitis. Also, Patel et al. (2016) recorded meningitis in three rabbits experimentally infected with $P$. multocida B2 through intranasal rout and observed bacterial emboli in the blood vessels of the brain. Contrarily, $P$. multocida meningitis has been reported to be rarely occurring in humans (Green et al., 2002).

The most significant microscopic lesions observed in the trachea and lunge of 
challenged rabbits in the present study were consistent with that previously finding of Mir et al (2001), Katoch et al. (2015) and Patel et al. (2016). Tracheal lesions, in the current investigation, were characterized by goblet cells hyperplasia and hypotrophy as well as neutrophils infiltration associated with desquamation of degenerating epithelial cells. The degeneration of epithelium probably, attributed to the effect of inflammatory cells when they migrate through the epithelium. Similarly, an increase in the number of goblet cells in the respiratory epithelium in rabbit fetuses exposed experimentally to $P$. multocida infection has been reported previously (Carrillo et al., 2012). Cells contain small secretory granules and are thought to produce watery secretions. Goblet cells have been reported to originate from other cell type in the respiratory epithelium (club cells), which act as progenitors of goblet cells after bronchiolar injury (Sleigh et al., 1988; Zhu et al., 2008). The increase in the goblet cell population in the respiratory epithelium following $P$. multocida infection in rabbits is a logic reaction because goblet cells are involved in mucin production that has defense mechanism against infections particularly in respiratory tract (Shuter et al., 1996; Scharfman et al., 1996). The prominent vascular lesions detected in lungs and trachea were consistent with observation of (Katoch et al., 2015; Patel et al., 2016; Alam et al., 2018). Our findings support those of Praveena et al. (2010) who verified the important role of pulmonary intravascular macrophages in induction of lung lesions in pasteurellosis, they mentioned that bacterial endotoxin activate these macrophages and may lead to influx of other inflammatory cells and cascading injury. They added that toxins products of $P$. multocida alone or in combination with products of inflammatory cells induce necrotic changes in the wall of pulmonary blood vessels and the injured wall of blood vessels may be responsible for edema and hemorrhages in alveoli. Additionally, Patel et al. (2016) reported that the bacterial toxin also causes necrosis of leukocytes with production of oat cells which become marked by streaming pattern of condensed chromatin material.

Although previous reports verified that pneumonic pasteurellosis is the main manifestation of the disease in rabbits challenged intranasally with the $P$. multocida (Jaglic et al., 2008), other parenchymatous organs like liver were also affected. The histopathological changes observed in the liver of challenged rabbits in the current study included diffuse hydropic degeneration of hepatocytes, few necrotic foci infiltrated with inflammatory cells, periportal mononuclear inflammatory cells infiltration associated with edema, congestion and fibrosis. These findings are consistent with previous results in experimentally infected rabbits with $P$. multocida (Alam et al., 2018), and $P$. multocida experimentally infected mice as well (Praveena et al., 2010). The most significant microscopic lesions observed in heart and spleen of challenged rabbits those reported by (Praveena et al., 2010) in $P$. multocida infected mice. These lesions included an acute cell injury that may be resulting from bacterial endotoxins or toxic proteins (Praveena et al., 2010).

\section{Conclusion}

It could be concluded from the current study that infection with $P$. multocida 
serotype A was not lethal to rabbits. Although the strain was essentially pneumotropic in nature, yet it caused lesions in other visceral organs, which in absence of bacteremia, could be attributed to the bacterial endotoxin during the pathogenesis of the disease.

\section{Conflict of interest statement}

The authors declare that they have no conflict of interest.

\section{References}

Al-Haddawi MH, Jasni S, Israf DA, Mutalib AR (2001). Ultrastructural pathology of nasal and tracheal mucosa of rabbits experimentally infected with Pasteurella multocida serotype D:1. Research in Veterinary Science, 70 (3): 191-197.

Al-Jeboori KH, Rasheed SS (2014). Snuffles disease in rabbits: 3- hematological parameters. International Journal of Advanced Biological Research, 4 (3): 332-333.

Alam RTM, Fawzi EM, Alkhalf MI, Alansari WS, Aleya L, Abdel-Daim MM (2018): Anti-Inflammatory, immunomodulatory, and antioxidant activities of allicin, norfloxacin, or their combination against pasteurella multocida infection in male New Zealand rabbits. Oxidative Medicine and Cellular Longevity, Vol. 2018, Article ID 1780956, 10 pages.

Asran EA, Khalil SA, Hegazy AM (2016). Identification and Molecular Analysis of Pasteurella Multocida Isolated from Rabbits. Alexandria Journal of Veterinary Sciences, 48 (1): 34-41.

Bancroft JD, Gambl M (2008): Theory and practice of histological techniques 5th ed., Churchill Livingstone. New York, Londone, Philadelphia.

Carrigan SD, Scott G, Tabrizian M (2004). Toward resolving the challenges of sepsis diagnosis. Clinical chemistry, 50:1301-1314.

Carrillo MP, Mart'inez N, Iregui CA (2012). "Lectin- mediated inhibition of Pasteurella multocida adherence to rabbit respiratory epithelium in vitro," in Abstracts II International Conference on Antimicrobial Research (ICAR '12), Lisbon, Portugal, 2012.

Carter GR (1987). Serological classification of Pasteurella multocida. Veterinary Record, 121: 382-383.

Chengappa MM, Myers RC, Carter GR (1982). Capsular and somatic types of Pasteurella multocida from rabbits. Canadian Journal of Comparative Medicine, 46: 437-439.

Committee for the Update of the Guide for the Care and Use of Laboratory Animals (2011): Guide for the Care and Use of Laboratory Animals. The National Academies Press 500 Fifth Street, NW Washington, DC 20001.

Dabo SM, Confer AW, Montelongo M, Lu YS (1999). Characterization of rabbit Pasteurella multocida isolates by use of whole-cell, outer-membrane, and polymerase chain reaction typing. Laboratory Animal Science, 49: 551559.

DeLong D, Manning PJ (1994). Bacterial diseases p. 129-170. In P.J. Manning, D.H. Ringler, C.E. Newcomer (Eds.), The Biology of the Laboratory Rabbits (2nd ed.). Academic Press, Inc., San Diego. 
DiGiacomo RF, Xu YM, Allen V, Hinton MH, Pearson GR (1991). Naturally acquired Pasteurella multocida infection in rabbits: clinicopathological aspects. Canadian Journal of Veterinary Research, 55: 234-238.

El-Ghawy M (1972). The bacteriological flora of respiratory tract of rabbits in health and disease [Master thesis in Bacteriology], Faculty Veterinary Medicine, Cairo University.

Glavits R, Magyar T (1990). The pathology of experimental respiratory infection with Pasturella multocida and Bordetell bronchiseptica in rabbits. Acta Veterinaria Hungarica, 38 (3): 211-215.

Green BT, Ramsey KM, Nolan PE (2002). Pasteurella multocida meningitis: case report and review of the last 11 y. Scandinavian Journal of Infectious Diseases, 34 (3): 213-217.

Harper M, Boyce JD, Adler B (2006). Pasteurella multocida pathogenesis: 125 years after Pasteur. FEMS Microbiology Letters, 265: 1-10.

Hoffbrand AV, Pettit JE (1993). Essential hematolog, 3rd ed. Blackwell scientific publication Oxford, London.

Hotchkiss EJ, Hodgson JC, Schmitt-van de Leemput E, Dagleish MP, Zadoks RN (2011). Molecular epidemiology of Pasteurella multocida in dairy and beef calves. Veterinary Microbiology, 151(3-4): 329-335.

Jaglic Z, Jeklova E, Leva L, Kummer V, Kucerova Z, Faldyna M, Maskova J, Nedbalcova K, Alexa P (2008). Experimental study of pathogenicity of Pasteurella multocida serogroup F in rabbits. Veterinary Microbiology, 126: 168-177.

Jaglic Z, Kucerova Z, Nedbalcova K, Kulich $\mathrm{P}$, Alexa P (2006). Characterisation of Pasteurella multocida isolated from rabbits in the Czech Republic. Veterinarni Medicina, 51 (5): 278287.

Katoch S, Verma L, Sharma M, Asrani RK, Kumar S, Chahota R, Verma S (2015). Experimental Study of the Pathogenicity of Pasteurella multocida Capsular Type B in Rabbits. Journal of Comparative Pathology, 153: 160-166.

Kpodekon M (1983). Experimental study of the pathogenesis of meningitis and encephalitis during pasteurellosis in rabbits. Annals of Veterinary Research, 14 (3): 217-224.

Mir MS, Dwivedi P, Charan K (2001). Pasteurella multocida-12: A induced clinic-pathological changes in rabbits. Indian Journal of Veterinary Pathology, 25 (1\&2): 24-27.

Nassar SA, Mohamed AH, Soufy H, Nasr SM (2013). "Protective effect of Egyptian propolis against rabbit pasteurellosis," BioMed Research International; 2013, Article ID 163724, 9 pages.

Numata M, Suzuki S, Miyazwa N, Miyashita A, Nagashima Y, Inoue S, Kaneko T, Okubo $T$ (1998). Inhibition of inducible nitric oxide synthase prevents LPS induced acute lung injury in dogs. Journal of Immunology, 160: 3031-3037.

Patel SJ, Joshi DV, Raval SH, Patel BJ, Patel JG, Chandel BS, Patel BK, Shah NM (2016), Clinicopathological studies of Pasteurella multocida B: 2 experimental infection in rabbits. 
Indian Journal of Animal Sciences, 86 (4): 380-386.

Petrova Y, Georgieva T, Georgiev I, Petrov V, Kalkanov I, Karadaev M, Stoev S (2017). Changes in red blood count parameters in New Zealand White rabbits after experimentally induced Pasteurella multocida infection. Bulgarian Journal of Veterinary Medicine, 20, Suppl., 1: 352-358.

Praveena PE, Periasamy S, Kumar AA, Singh N (2010). Cytokine profiles, apoptosis and pathology of experimental Pasteurella multocidaserotype A1 infection in mice. Research in Veterinary Science, 89: 332-339.

Rameshkumar P, Kumar AA, Ravindran R, Paliwal OP (2006). Studies on experimental pasteurellosis in rabbits inoculated with Pasteurella multocida serotype $\mathrm{A} /$ : 3 . Indian Journal of Veterinary Pathology, 30 (2): 32-35.

Rimler RB, Rhoades KR (1989), Solubilization of membraneassociated cross-protection factor(s) of Pasteurella multocida. Avian Diseases, 33: 258-263.

Ruble RP, Cullor JS, Brooks DL (1999). The observation of reactive thrombocytosis in New Zealand white rabbits in response to experimental Pasteurella multocida infection. Blood Cells, Molecules, and Diseases, 25(2): 95-102.

Sanchez S, Mizan S, Quist C, Schroder P, Juneau M, Dawe D, Ritchie B, Lee MD (2004). Serological response to Pasteurella multocida NanH sialidase in persistently colonized rabbits. Clinical and Diagnostic
Laboratory Immunology, 11: 825834.

Scharfman A, Van Brussel E, Houdret N, Lamblin G, Roussel P (1996). Interactions between glycoconjugates from human respiratory airways and pseudomonas aeruginosa. American Journal of Respiratory and Critical Care Medicine, 154: 163-169.

Shuter J, Hatcher VB, Lowy FD (1996). Staphylococcus aureus binding to human nasal mucin. Infection and Immunity, 64: 310-318.

Sleigh MA, Blake JR, Liron N (1988). The propulsion of mucus by cilia. The American Review of Respiratory Disease, 137: 726-741.

Stelian B, Ivava S, Zaulet M, Otelea AR, Rotaru E, Judith I, Danes D (2011). Molecular epidemiology investigations in 8 Romanian outbreaks of rabbit pasteurellosis by Pulsed-Field gel electrophoresis. Romanian Biotechnoological Letters, 16: 5841-5849.

Suelam IIA, Samie LK (2011). "Molecular diversity of Pasteurella multocida isolated from different rabbit outbreaks at Zagazig suburbs, Egypt," Global Veterinaria, 6 (2): 208-212.

Suvarna S K, Layton C, Bancroft J D (2013). Bancroft's Theory and Practice of Histological Techniques. 7th edn. Churchill Livingstone Elsevier.

Zhu Y, Ehre C, Abdullah LH, Sheehan JK, Roy M, Evans CM, Dickey BF, Davis CW (2008). Munc13-2-/baseline secretion defect reveals source of oligomeric mucins in mouse airways. The Journal of Physiology, 586: 1977-1992. 